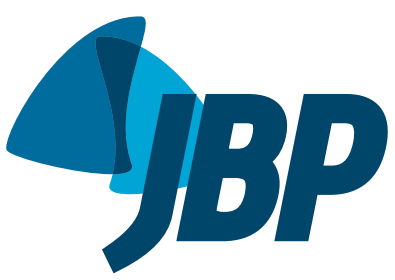

\section{PRACTICAL SCENARIO}

The authors of a case report ${ }^{(1)}$ describe the success and safety of treating a 65-year-old patient admitted to the hospital with severe COPD and huge emphysematous bullae in the right middle lobe and bronchoscopic lung volume reduction (BLVR). They placed an endobronchial valve in the right middle bronchus after confirming that there was no collateral ventilation. ${ }^{(1)}$ The authors describe the complete treatment regimen given to the patient and report that the huge bullae remained small one week later and disappeared at two months, with the improvement of pulmonary function, symptoms, and quality of life with no signs of obstruction, pneumonia, or pneumothorax. The authors concluded that BLVR may serve as an alternative treatment among selected patients with giant emphysematous bullae.

\section{BACKGROUND}

A case report is a comprehensive narrative that provides a clear and detailed description of unique medical experiences with patients that can impact both clinical and research practices. It is very important to publish those experiences, such as in our example, as case reports. Such narratives serve to increase existing knowledge on important clinical topics and to provide insights into new or rare diseases and to nonconventional patient care that can later be more formally evaluated using more sophisticated study designs, such as randomized controlled trials.

In the case report described above, ${ }^{(1)}$ the authors report their experience treating a patient with a specific clinical pattern of COPD with BLVR, because patients with both COPD and giant emphysematous bullae have been excluded from previous treatment studies. The reason for excluding patients with this clinical presentation was that this type of emphysema is a predictor of operative mortality.

We highly recommend that all clinicians, and especially clinician-scientists, take the time to report interesting and unique cases of patients they treat in their home setting that could eventually affect the health of similar patients worldwide. Publishing case reports is an important first step in contributing to answer new questions and guiding informed patient-centered clinical practices. Additionally, for early-stage clinicians, a case report is sometimes the first opportunity to become a published author, since there is no requirement for design or implementation of a clinical research study. Although case reports are at the base of the evidence-based pyramid and are often mistakenly perceived as unimportant in medical science, we highlight that the evidence-based pyramid serves as a guide for clinicians' decision-making processes as a reminder that decisions and recommendations for patients should be based on research data resulting from robust study designs, such as clinical trials, but it does not imply that case reports are not valid.

\section{USING ESTABLISHED GUIDELINES TO PUBLISH CASE REPORTS}

To write and publish high-quality case reports, we highly recommend the use of the CARE (CAse REport) Statement and Checklist ${ }^{(2)}$ for the accurate report of information that should be provided in each section of the case report (Table 1 ).

Table 1. Examples of some of the items on the CARE (CAse REport) Statement and Checklist. ${ }^{(2)}$

\begin{tabular}{|c|c|c|}
\hline Item & Topic & Checklist Item description \\
\hline 1 & Title & Include in the title the name of the study design: "case report". \\
\hline $3 a$ & Abstract Introduction & What is unique about this case? What does it add to the medical literature? \\
\hline $5 a$ & Patient Information & De-identify demographic information and other specific patient information. \\
\hline $9 a$ & Therapeutic Intervention & $\begin{array}{l}\text { Describe types of intervention (such as pharmacological, surgical, preventive, and } \\
\text { self-care). }\end{array}$ \\
\hline $10 \mathrm{~b}$ & Follow-up and outcomes & Provide important follow-up diagnostic/nondiagnostic test results. \\
\hline $11 \mathrm{a}$ & Discussion & Discuss the strengths and limitations in your approach to this case. \\
\hline
\end{tabular}

\title{
REFERENCES
}

Lee EG, Rhee CK. Bronchoscopic lung volume reduction using an endobronchial valve to treat a huge emphysematous bullae: a case report. BMC Pulm Med. 2019;19(1):92. https://doi.org/10.1186/s12890$019-0849-z$
2. Riley DS, Barber MS. Kienle GS, Aronson JK, von Schoen-Angerer T, Tugwell $P$, et. al. CARE guidelines for case reports: explanation and elaboration document. J Clin Epidemiol. 2017;89:218-235. https://doi. org/10.1016/.j.jclinepi.2017.04.026

1. Methods in Epidemiologic, Clinical, and Operations Research-MECOR-program, American Thoracic Society/Asociación Latinoamericana del Tórax Montevideo, Uruguay.

2. Department of Preventive Medicine, Keck School of Medicine, University of Southern California, Los Angeles, CA, USA.

3. Divisão de Pneumologia, Instituto do Coração, Hospital das Clínicas, Faculdade de Medicina, Universidade de São Paulo, São Paulo (SP) Brasil.

a. (iD) http://orcid.org/0000-0001-5742-2157; b. (iD) http://orcid.org/0000-0001-6548-1384 